\title{
Effects of job conditions, occupational stress, and emotional intelligence on chronic fatigue among Chinese nurses: a cross-sectional study
}

This article was published in the following Dove Press journal: Psychology Research and Behavior Management

\author{
Hao Huang' \\ Li Liu' \\ Shihan Yang' \\ Xiaoxing Cui ${ }^{2}$ \\ Junfeng Zhang ${ }^{2,3}$
}

Hui Wu'

'Department of Social Medicine, School of Public Health, China Medical University, Shenyang II0I22, People's Republic of China; ${ }^{2}$ Nicholas School of Environment, Duke University, Durham, NC 27708, USA; ${ }^{3}$ Duke Global Health Institute, Duke University, Durham, NC 277I0, USA
Correspondence: Hui Wu

Department of Social Medicine, School of Public Health, China Medical University,

77 Puhe Road, Shenyang II0I22, People's

Republic of China

Tel +86 I89 0091 0568

Email hwu@cmu.edu.cn
Purpose: Nurses are undertaking considerable emotional and physical work, which may lead to unrecoverable fatigue. This study aimed to evaluate the level of chronic fatigue and explore its associated factors among Chinese nurses in the hope of providing scientific evidence for fatigue-reduction strategies.

Methods: This cross-sectional study was carried out in Liaoning Province, China in 2018. The study recruited 700 nurses and collected 566 effective respondents. Chronic fatigue, demographic factors, job conditions, and emotional intelligence were assessed through questionnaires. Chronic fatigue was assessed with the Fatigue Scale 11, occupational stress with the Effort-Reward Imbalance Questionnaire, and emotional intelligence with the Wong and Law Emotional Intelligence Scale. Hierarchical multiple regression was used to explore factors related to chronic fatigue and to test the moderating effect of emotional intelligence on the association between occupational stress and chronic fatigue. Simple slope analysis was conducted to visualize the interaction.

Results: The mean score of chronic fatigue among the Chinese nurses was $17.14 \pm 6.16$. Being married, having long weekly work time, working night shifts, and discontent with the nurse-patient relationship were positively associated with chronic fatigue. Effort:reward ratio, overcommitment, and emotional intelligence were important factors related to chronic fatigue. Emotional intelligence played a moderating role in the relationship between the effort:reward ratio and chronic fatigue. When emotional intelligence was higher, the effect of the effort:reward ratio on chronic fatigue became weaker.

Conclusion: Most nurses surveyed in China might have relatively high levels of chronic fatigue. Our results highlight the importance of interventions on these factors for the reduction of fatigue among nurses in China. Providing more opportunities and support and developing emotional intelligence are crucial strategies to reduce chronic fatigue among nurses in China.

Keywords: chronic fatigue, occupational stress, emotional intelligence, nurses, moderating effect

\section{Introduction}

Fatigue is a common condition, and $5 \%-20 \%$ of the general population is reported to suffer from it. ${ }^{1-3}$ Fatigue is defined by the North American Nursing Diagnosis Association as a self-recognized state in which an individual experiences decreased labor ability because of physical and mental overwork and feels an overwhelming persistent sense of tiredness, weakness, and exhaustion that is not moderated by rest. ${ }^{4}$ Several mental and physical consequences can result from fatigue, including 
mood changes, decreased work capability, physical pain, and diseases, which can lead to considerable economic loss due to decreased productivity and increased healthcare expenditure. ${ }^{5}$ Obviously, unlike burnout or compassion fatigue, which operate only at the psychological level, the fatigue that we are interested in is a combination of psychological and physical levels. Generally, fatigue is divided into acute fatigue and chronic fatigue. Acute fatigue is a temporary state, while chronic fatigue is often considered an illness or long-term condition. ${ }^{6}$ In this study, our investigation focused on chronic fatigue.

Chronic fatigue can be common among nurses. It has been reported that the level of fatigue is considerably high among nurses. ${ }^{7}$ Another study also reported moderate-high levels of acute fatigue and moderate levels of chronic fatigue among nurses. ${ }^{8}$ As nurses are an essential workforce at hospitals, chronic fatigue among them can have substantial underlying impact, including job dissatisfaction, adverse health outcomes, memory loss, prolonged reaction time, and decreased decision-making abilities, which can make fatigued nurses more prone to medical errors and may affect the quality of patient care delivered. ${ }^{5,9}$ In summary, the considerable impact of chronic fatigue on nurses and patients necessitates the investigation of chronic fatigue and its associated factors.

Previous studies on fatigue have suggested that it is associated with demographic factors and work conditions. Finsterer et $\mathrm{al}^{10}$ reported that fatigue was influenced by age and sex, specifically older age and being female predisposing individuals to fatigue. Another study reported an association between higher education level and higher level of fatigue among nurses. ${ }^{11}$ Chen et $\mathrm{al}^{8}$ found that married nurses experienced higher level of fatigue compared to nurses with other marital status. As for work conditions, Piko ${ }^{12}$ reported that long working hours and high frequency of night shifts had strongly positive associations with chronic fatigue among nurses. In addition, a previous study reported that difficulties in the nursepatient relationship could induce adverse health outcomes, such as depressive symptoms among nurses. ${ }^{13}$ Bültmann et $\mathrm{al}^{14}$ suggested that relationships with others at work also played a major role in the development of fatigue, as specific psychosocial experiences can exacerbate mental fatigue. Therefore, challenges in the nurse-patient relationship might have a significant impact on chronic fatigue among Chinese nurses.

More importantly, under working conditions in China, higher stress at the workplace is commonly found among nurses, with a positive relationship with fatigue. ${ }^{15,16}$ The effort-reward imbalance (ERI) model can be a helpful tool in quantifying occupational stress. ${ }^{17}$ According to the ERI model, job stress arises from an individual's interactions with the psychosocial work environment. The model has three core elements: extrinsic effort, reward, and overcommitment. Extrinsic effort represents external results of one's demands or obligations imposed on themselves. Reward mainly comprises esteem, salary, and career opportunities. Overcommitment is defined as a personality characteristic reflecting a strong desire to be approved and valued. ${ }^{17}$ Imbalance between extrinsic efforts and rewards or high overcommitment will introduce occupational stress, which can trigger psychosomatic responses and bring about or aggravate fatigue. ${ }^{18,19}$ As a result, occupational stress may be a key factor associated with chronic fatigue among nurses in China.

Increasing occupational stress and the constant need to express empathy when delivering patient care can result in potential difficulties in nurse-patient relationships. Emotional intelligence can be one of the resources utilized by nurses to cope with these emerging challenges. Emotional intelligence has been defined as the ability of individuals to understand the emotions of themselves or others and to identify and use this information to control their own thinking or behavior. ${ }^{20}$ Generally, it is believed that utilizing emotional intelligence on the job can have impacts on occupational stress, burnout, work engagement, and interpersonal relationships. ${ }^{21,22}$ Nurses who possess high emotional intelligence have also been shown to have good health and general well-being. ${ }^{23,24}$ As such, emotional intelligence may be a crucial factor related to chronic fatigue at work. In addition, to our knowledge, emotional intelligence can regulate individual stress and reduce negative mood. ${ }^{25,26}$ Sharma et al ${ }^{27}$ reported emotional intelligence moderated the relationship between occupational stress and psychological health. Görgens-Ekermans et $\mathrm{al}^{28}$ also indicated that emotional intelligence played a moderating role in the association between work stress and burnout. Therefore, emotional intelligence seems likely to be a moderator in the relationship between occupational stress and chronic fatigue among nurses in China. However, few studies have explored such associations, which necessitates our study.

In summary, the present study aims to explore associated factors of chronic fatigue among nurses in Liaoning Province of China and to examine whether emotional intelligence has a moderating effect in the relationship between occupational stress and chronic fatigue among them. 


\section{Methods}

\section{Ethics statement}

The procedures of this study were reviewed and approved by the institutional review board of China Medical University. Written informed consent was obtained from each participant. All data collected from the subjects were kept anonymous and confidential to protect their privacy.

\section{Study design and data collection}

This cross-sectional study was conducted in Liaoning Province, China in 2018. Participants were sampled through a two-stage method. First, Liaoning Province consists of five regions: eastern, western, southern, northern, and central. In each region, two tertiary hospitals with $>500$ beds were randomly selected, totaling ten large hospitals. A total of 70 nurses as volunteers were randomly selected in each sampled hospital, totaling 700 nurses. Nurses who had worked $<1$ year were excluded from this study. After informed consent had been obtained, a selfadministered questionnaire, which needed about 15 minutes to complete, was distributed to each study subject. Finally, we collected 566 questionnaires, with an effective rate of $80.9 \%$.

\section{Measurement of fatigue}

The Fatigue Scale (FS) compiled by Chalder et al has been used and validated by a number of studies for measuring the level of chronic fatigue. ${ }^{29}$ In our study, we used the Chinese mainland version of the scale (FS11), a translation of the original Chalder FS. ${ }^{30}$ The FS11 survey comprises eleven questions, each of which has four options with a score of $0-3(0=$ less than usual to $3=$ much more than usual), with a total score ranging from 0 to 33 . Higher scores indicate a higher level of chronic fatigue. Its validity and reliability have been tested among the Chinese population by Jing et al. ${ }^{31}$ Cronbach's $\alpha$-coefficient for the FS11 in this study was 0.724 .

\section{Measurement of demographic characteristics}

Four demographic characteristics were collected from a self-designed questionnaire: age, sex, marital status, and education. Age was collected as a continuous variable. Options for marital status included unmarried, married/ cohabitating, and divorced/widow/separated. Education was divided into "junior college and below", and "college and above".

\section{Measurement of job conditions}

Three job factors - weekly work time, night shifts, and the nurse-patient relationship - were assessed with three selfdesigned questions. Using the domestic working-hour standard in China as the cut point, weekly work time was divided into $\leq 40$ hours/week and $>40$ hours/week. The night-shift question was yes/no. Nurse-patient relationships were assessed with the question "How often have you been dissatisfied with the nurse-patient relationship at work?", with five possible answers: never, rarely, sometimes, frequently, and always. The response was further classified into satisfaction (never), moderate dissatisfaction (rarely/ sometimes), or high dissatisfaction (frequently/always).

\section{Measurement of occupational stress}

Occupational stress was measured by the ERI Questionnaire. The ERI Questionnaire was originally designed by Siegrist in 1996, and was translated to Chinese by Li et al. ${ }^{32,33}$ The ERI Questionnaire has been used widely by researchers and has demonstrated adequate reliability and validity among sampled populations in China. ${ }^{33,34}$ The 23-item ERI Questionnaire measures extrinsic effort (six items), reward (eleven items), and overcommitment (six items). It uses a 5point Likert scale for extrinsic effort and reward $(1=$ no stressful experiences to $5=$ very distressed) and a 4-point Likert scale for overcommitment $(1=$ strongly disagree to 4 $=$ strongly agree). Effort:reward ratio was calculated by dividing effort by reward and multiplied by $11 / 6$ to correct for the item-number difference in the two dimensions. An effort:reward ratio $>1$ means high cost and low gain, reflecting a risk-imbalance condition. A higher effort:reward ratio and overcommitment indicate higher occupational stress. Reliability measured by Cronbach's $\alpha$-coefficient for extrinsic effort, reward, and overcommitment in this study were $0.866,0.762$, and 0.756 , respectively.

\section{Measurement of emotional intelligence}

Emotional intelligence was measured using the Wong and Law Emotional Intelligence Scale (WLEIS). ${ }^{35}$ This scale has been translated into Chinese and shown to have adequate reliability and validity among individuals surveyed in China. ${ }^{36}$ The WLEIS is a 16 -item scale consisting of four dimensions: self-emotion appraisal, appraisal of other's emotions, regulation of emotion, and use of emotion. In this article, we focus on total emotional intelligence. The response format is a 7-point Likert scale, ranging from $0=$ strongly disagree to $6=$ strongly agree, 
with higher scores indicating higher emotional intelligence. Cronbach's $\alpha$-coefficient for the total scale was 0.848 .

\section{Statistical analyses}

Mean fatigue scores in different categories of demographic and job-condition factors were tested by $t$-test or one-way ANOVA. Pearson correlation analysis was used to analyze correlations among age, occupational stress, emotional intelligence, and chronic fatigue. All variables related to fatigue in univariate analysis $(P<0.05)$ were entered in the hierarchical multiple regression model, which was used to estimate the contribution of different factors to the level of chronic fatigue and to evaluate the moderating effect of emotional intelligence on the relationship between occupational stress and chronic fatigue. In the model, potential control variables were entered in step 1. Occupational stress and emotional intelligence were added in step 2. Finally, the product of occupational stress and emotional intelligence was added in step 3. The hypothesis of the moderating effect of emotional intelligence was supported if the interaction were significant. Simple slope analysis was conducted to visualize the interaction term. The variance inflation factor was used to estimate whether a regression coefficient had increased because of collinearity. In the present study, factor values $<10$ were taken as multicollinearity not being an issue in the estimate. All statistical analyses were performed with SPSS for Windows 17.0 , with two-tailed $P<0.05$ considered statistically significant.

\section{Results}

\section{Demographic characteristics and job conditions}

The average score of chronic fatigue among the nurses surveyed was $17.14 \pm 6.16$. Results of univariate analyses between chronic fatigue and each factor of demographic characteristics and job conditions of study subjects are shown in Table 1. Nurses who responded to the questionnaires were aged $34.35 \pm 8.95$ years, $68.6 \%$ were married, and $52.7 \%$ of them had an education level of college and above. The proportion of the nurses whose weekly work was $>40$ hours was $81.8 \%, 56.9 \%$ did night shifts, and $19.4 \%$ of felt high dissatisfaction with the nurse-patient relationship. Furthermore, except sex, all the variables marital status, education, weekly work time, night shifts, and nurse-patient relationship - were significantly associated with chronic fatigue.

\section{Correlations among chronic fatigue, occupational stress, and emotional intelligence}

Correlation coefficients between continuous variables are presented in Table 2. The level of chronic fatigue was positively correlated with effort:reward ratio and overcommitment and negatively correlated with emotional intelligence. Emotional intelligence was negatively correlated with effort:reward ratio.

\section{Associations of demographic characteristics, job conditions, occupational stress, and emotional intelligence with level of chronic fatigue by hierarchical multiple regression analyses}

In hierarchical regression models, demographic variables (including age, marital status, and education) and job conditions (including weekly work hours, night shifts, and nurse-patient relationship) were entered in step 1 . Occupational stress (namely effort:reward ratio and overcommitment) and emotional intelligence were added in step 2. The interaction of occupational stress and emotional intelligence was entered in step 3 .

As shown in Table 3, in step 1 marital status, weekly work hours, night shifts, and nurse-patient relationship were factors related to chronic fatigue. The linear combination of these variables partially explained the variance in chronic fatigue (adjusted $R^{2}=0.146, \Delta R^{2}=0.156 ; P<0.01$ ). In step 2, effort: reward ratio was found to be significantly and positively related to chronic fatigue $(\beta=0.282, P<0.01$ ), while emotional intelligence was significantly and negatively associated with chronic fatigue $(\beta=-0.267, P<0.01)$. Effort:reward ratio and emotional intelligence had significant effects on chronic fatigue (adjusted $R^{2}=0.297, \Delta R^{2}=0.152 ; P<0.01$ ). In step 3, the effort:reward ratio $\times$ emotional intelligence interaction was significantly and positively associated with chronic fatigue $(\beta=0.158, P<0.01)$. Therefore, emotional intelligence played a moderating role in the relationship between effort:reward ratio and chronic fatigue. Simple slope analysis of the interaction is presented in Figure 1, which shows that the impact of effort:reward ratio on chronic fatigue was different in low (1 SD below mean, $\beta=0.444 ; \quad P<0.001)$, mean $(\beta=0.308$, $P<0.001$ ), and high ( $1 \mathrm{SD}$ above mean, $\beta=0.172 ; P<0.001$ ) levels of emotional intelligence. When emotional intelligence was higher, the effect of effort:reward ratio on chronic fatigue became weaker. 
Table I Demographic characteristics and job conditions of study participants and univariate analysis of factors in relation to level of chronic fatigue $(n=566)$

\begin{tabular}{|c|c|c|c|}
\hline Variable & n (\%) & Chronic fatigue (mean \pm SD) & $P$-value \\
\hline Sex & & & 0.931 \\
\hline Female & $552(97.5 \%)$ & $17.00 \pm 6.32$ & \\
\hline Male & $14(2.4 \%)$ & $17.14 \pm 6.16$ & \\
\hline Marital status & & & 0.001 \\
\hline Unmarried & $160(28.3 \%)$ & $15.58 \pm 5.50$ & \\
\hline Married/cohabitating & $388(68.6 \%)$ & $17.75 \pm 6.28$ & \\
\hline Divorced/widow/separated & $18(3.1 \%)$ & $|8.00 \pm 7.0|$ & \\
\hline Education & & & 0.002 \\
\hline Junior college and below & $268(47.3 \%)$ & $16.29 \pm 6.23$ & \\
\hline College and above & $298(52.7 \%)$ & $17.90 \pm 6.01$ & \\
\hline Weekly work time & & & 0.001 \\
\hline$\leq 40$ hours & $103(18.2 \%)$ & $15.24 \pm 7.04$ & \\
\hline$>40$ hours & $463(81.8 \%)$ & $17.56 \pm 5.88$ & \\
\hline Night shifts & & & $<0.001$ \\
\hline No & $244(43.1 \%)$ & $|8.12 \pm 5.9|$ & \\
\hline Yes & $322(56.9 \%)$ & $15.85 \pm 6.26$ & \\
\hline Dissatisfaction with nurse-patient relationship & & & $<0.001$ \\
\hline Satisfaction & $30(5.3 \%)$ & $12.57 \pm 6.50$ & \\
\hline Moderate dissatisfaction & $426(75.3 \%)$ & $16.60 \pm 5.72$ & \\
\hline High dissatisfaction & $110(19.4 \%)$ & $20.47 \pm 6.33$ & \\
\hline
\end{tabular}

Table 2 Correlation coefficients among continuous variables $(n=566)$

\begin{tabular}{|l|l|l|l|l|l|}
\hline Variable & Mean \pm SD & I & $\mathbf{2}$ & $\mathbf{3}$ & $\mathbf{4}$ \\
\hline I. Chronic fatigue & $17.14 \pm 6.16$ & & & & \\
2. Age & $34.35 \pm 8.95$ & -0.017 & & & \\
3. Effort:reward ratio & $1.07 \pm 0.41$ & $0.405^{* *}$ & -0.047 & & \\
4. Overcommitment & $16.23 \pm 3.09$ & $0.337^{* *}$ & 0.058 & $0.419^{* *}$ & -0.019 \\
5. Emotional intelligence & $60.25 \pm 16.01$ & $-0.359 * *$ & 0.081 & $-0.186^{* *}$ & \\
\hline
\end{tabular}

Note: $*_{*}^{*}<0.01$ (two-tailed).

As shown in Table 4, in step 2, after adjustment control variables, overcommitment was found to be significantly and positively related to chronic fatigue $(\beta=0.275, P<0.01)$, while emotional intelligence was significantly and negatively associated with chronic fatigue $(\beta=-0.321, \quad P<0.01)$. Overcommitment and emotional intelligence had significant effects on chronic fatigue (adjusted $R^{2}=0.297, \Delta R^{2}=0.152$; $P<0.01$ ). In step 3 , the overcommitment $\times$ emotional intelligence interaction term was not significantly associated with chronic fatigue $(\beta=0.019, P>0.05)$. Therefore, emotional intelligence did not moderate the relationship between overcommitment and chronic fatigue.

\section{Discussion}

The results of this study showed that the average chronic fatigue score of nurses surveyed in China was 17.14 \pm 6.16 . This score was higher than that reported by general communities and close to scores reported by patients. ${ }^{37-39}$ This discrepancy may partly stem from the different survey conditions and administration used. However, this finding indicated that the chronic fatigue among nurses was a very noticeable issue. As such, finding the related factors of chronic fatigue and its relevant interventions is needed in reducing chronic fatigue among nurses. 
Table 3 Associations of demographic characteristics, job conditions, effort:reward ratio, and emotional intelligence with chronic fatigue $(n=566)$

\begin{tabular}{|l|l|l|l|}
\hline Variable & Step I & Step 2 & Step 3 \\
\hline Age & $-0.127^{*}$ & -0.070 & -0.078 \\
Married vs unmarried & $0.185^{* *}$ & $0.148^{* *}$ & $0.162^{* *}$ \\
Divorced/widow/separated vs unmarried & $0.110^{*}$ & 0.079 & 0.077 \\
Education & 0.058 & 0.049 & 0.044 \\
Weekly work time & $0.094^{*}$ & $0.082^{*}$ & $0.072^{*}$ \\
Night shifts & $0.148^{* *}$ & $0.124^{* *}$ & $0.113^{* *}$ \\
Nurse-patient relationship & $0.251^{* *}$ & $0.107^{* *}$ & $0.098^{*}$ \\
Effort:reward ratio & & $0.282^{* *}$ & $0.305^{* *}$ \\
Emotional intelligence & & $-0.267^{* *}$ & $-0.28 I^{* *}$ \\
Effort:reward ratio $\times$ emotional intelligence & & & $0.158^{* *}$ \\
F & $14.748^{* *}$ & $27.503^{* *}$ & $27.59 I^{* *}$ \\
Adjusted $R^{2}$ & 0.146 & 0.297 & 0.320 \\
$\Delta R^{2}$ & 0.156 & 0.152 & 0.024 \\
\hline
\end{tabular}

Notes: ${ }^{*} p<0.05 ; * * p<0.01$ (two-tailed).

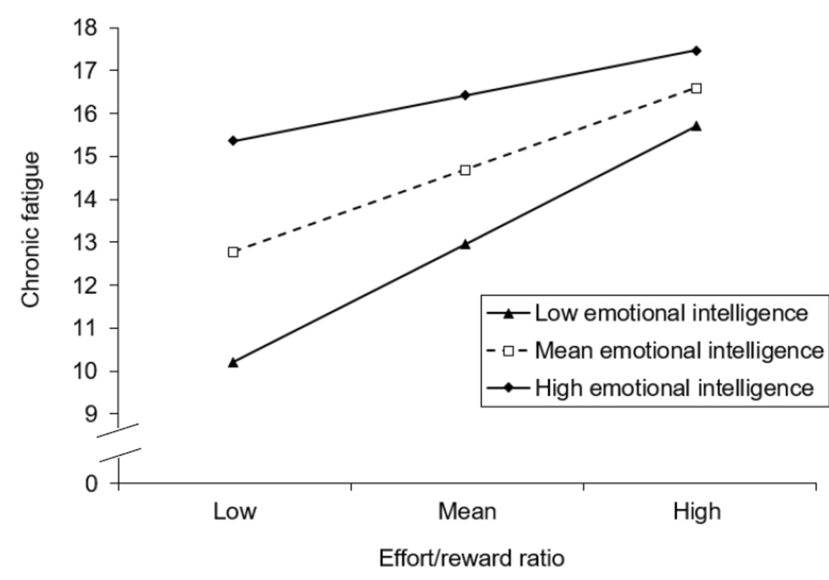

Figure I Simple slope plot of the interaction between effort:reward ratio and emotional intelligence on chronic fatigue.

In our study, we found that married status was significantly associated with chronic fatigue, consistently with previous studies. ${ }^{89}$ One possible reason might be that due to social and cultural norms, married nurses not only work hard in hospital to provide high-level service but also undertake housework, care for children, and support the elderly at home. Compared to nurses of other marital status, married nurses in China also need to spend considerable mental energy on working with relationships with husbands and parents-in-law. Therefore, this demand in balancing work-family time may contribute to additional fatigue. ${ }^{40}$ As such, personal time with family should be one of the factors considered when arranging the shifts of nurses. A flexible workingschedule system can effectively solve this problem. However, it is not necessarily suitable for medical staff in China, due to the heavy workload. Therefore, the relevant strategies need to be further studied.

We also found working-environment factors were importantly related to the level of chronic fatigue among nurses surveyed. Specifically, long weekly work time, night shifts, and dissatisfaction with the nurse-patient relationship were found to be significantly related to chronic fatigue, similarly to the findings of previous studies. ${ }^{8,41,42}$ More than $80 \%$ of nurses surveyed in this study had weekly work time $>40$ hours, which is higher than the domestic standard in China. Work duration might be prolonged to meet the considerable number of patients and related workloads at hospitals. This prolongation of work time can leave nurses with less time to relax and recharge, which impedes the timely reduction of fatigue. As for night shifts, it is well accepted that working at night requires a lot of energy and is more likely to lead to the disorder of body rhythms, which may have a serious impact on fatigue of nurses. ${ }^{43}$ In addition, we found nearly $20 \%$ of nurses were highly dissatisfied with the nurse-patient relationship. In fact, challenges in the nurse-patient relationship are on the rise in China. ${ }^{44}$ At present, patients expect medical service of higher quality, while nurses are short-staffed to accommodate such expectations, which generates conflicts in the nursepatient relationship. Furthermore, due to heavy workload, nurses have limited time to communicate with patients, which can also contribute to nurse-patient conflict, triggering negative emotions that contribute to perceived fatigue. ${ }^{44,45}$ As a result, interventions might be needed to reduce the workload and work time of nurses, such as increasing the number of nurses that can share the workload and reducing night-shift frequency. In addition, hospital administrators should improve 
Table 4 Associations of demographic characteristics, job conditions, overcommitment, and emotional intelligence with chronic fatigue $(n=566)$

\begin{tabular}{|l|l|l|l|}
\hline Variable & Step I & Step 2 & Step 3 \\
\hline Age & -0.127 & -0.085 & -0.084 \\
Married vs unmarried & $0.185^{* *}$ & $0.134^{* *}$ & $0.134^{* *}$ \\
Divorced/widow/separated vs unmarried & 0.110 & 0.065 & 0.066 \\
Education & 0.058 & 0.073 & 0.074 \\
Weekly work time & $0.094^{*}$ & $0.077^{*}$ & $0.075^{*}$ \\
Night shifts & $0.148^{* *}$ & $0.096^{*}$ & $0.097^{* *}$ \\
Nurse-patient relationship & $0.25 I^{* *}$ & $0.13 I^{* *}$ & $0.130^{* *}$ \\
Overcommitment & & $0.275^{* *}$ & $0.274^{* *}$ \\
Emotional intelligence & & $-0.319^{* *}$ & $-0.32 I^{* *}$ \\
Overcommitment $\times$ emotional intelligence & & & 0.019 \\
$F$ & $14.748^{* *}$ & $27.480^{* *}$ & $24.728^{* *}$ \\
Adjusted $R^{2}$ & 0.146 & 0.297 & 0.296 \\
$\Delta R^{2}$ & 0.156 & 0.152 & $<0.001$ \\
\hline
\end{tabular}

Notes: $* p<0.05 ; * * p<0.01$ (two-tailed).

protocols to increase service efficiency, but also enhance nurses' communication and nursing skills, and organize some activities involving both nurses and patients to improve the relationship between them.

The results also revealed that effort:reward ratio and overcommitment were significantly and strongly associated with fatigue. Previous studies had similar findings, and suggested that the imbalance in effort:reward ration and overcommitment can have direct effects on burnout. ${ }^{46,47}$ Nurses in China are undertaking significant workloads while receiving somewhat disproportional reward, including relatively low pay, insufficient respect from patients, and limited opportunities of promotion and further education at the workplace. Imbalance between efforts and rewards can bring nurses a feeling of injustice and have a negative impact on their self-esteem and emotion. ${ }^{48}$ The higher this imbalance, the more the emotional exhaustion and occupational stress, contributing to higher levels of fatigue. ${ }^{49,50} \mathrm{On}$ the other hand, to our knowledge, medical work requires a lot of responsibilities, which tends to produce high overcommitment among medical staff. The higher the level of overcommitment of nurses, the higher the possibility that they will devote themselves to work, which can trigger additional stress. Long-term accumulated psychological pressure will lead to fatigue. As one of the possible solutions, hospitals can establish more reward mechanisms for nurses, including higher compensation and opportunities for career advancement and further education, which could bolster their professional identity and job satisfaction to balance overcommitment.
In this study, emotional intelligence was found to have a negative association with the level of chronic fatigue. In addition, we also found that emotional intelligence moderated the association of effort:reward ratio with chronic fatigue, which partly confirmed our hypothesis. Results of the simple slope analysis showed that the higher the emotional intelligence, the weaker the effect of the effort: reward ratio on chronic fatigue. Emotional intelligence is one of the personal resources that can adjust psychological factors by regulating emotions and help release pressure proactively. ${ }^{25,51,52}$ As a result, nurses who have high emotional intelligence may combat fatigue better, as they can regulate their negative emotions, relax themselves in timely fashion,and more easily recognize and manage the stress. This finding indicated that if occupational stressors are hard be reduce effectively, improving emotional intelligence may be a good way to minimize the negative impact of occupational stress on chronic fatigue. However, we did not find an interaction between overcommitment and emotional intelligence on chronic fatigue, which needs further research. Nevertheless, the significant effect of emotional intelligence on fatigue should be highlighted when formulating solutions for fatigue reduction. As emotional intelligence can be developed, hospitals can set up programs that facilitate the growth of nurses' emotional intelligence to improve their ability to respond to negative emotions and help alleviate fatigue, eg, introducing self-control and self-regulation strategies for nurses to release psychological pressure and to regulate emotions. ${ }^{53,54}$ 
Several limitations must be mentioned. The cross-sectional design of this study keeps us from drawing any conclusion of causal relationships between the factors examined and chronic fatigue. Future longitudinal studies are needed for exploration of causal relationships. Secondly, participations in this study were recruited from tertiary hospitals with $>500$ beds, and working conditions there might be different from small clinics and thus limit extrapolation to nurses who work in other type of clinical facilities. Thirdly, data were collected by the subjective measure of self-reported questionnaires from the subjects, which may be subject to recall bias and response bias. Our study tried to minimize such biases by using the FS11, ERI, and WLEIS, that have been well validated for application among subjects in China.

\section{Conclusion}

In summary, based on this cross-sectional survey, our findings revealed that most nurses surveyed in China might have relatively high levels of chronic fatigue. Demographic factors, work conditions, occupational stress, and emotional intelligence were related to the development of chronic fatigue. Emotional intelligence moderated the association of effort: reward ratio with chronic fatigue. Our results highlight the importance of intervention on these factors for the reduction of fatigue among nurses in China. Providing more opportunities and support, adjusting job conditions, utilizing self-control, and developing emotional intelligence are crucial strategies to reduce chronic fatigue among nurses in China.

\section{Ethics approval and informed consent}

The procedures of this study were reviewed and approved by the Institutional Review Board of China Medical University. Written informed consent was obtained from each participant. All data collected from the subjects was kept anonymous and confidential to protect the privacy of the study subjects.

\section{Acknowledgments}

The authors would like to thank all the administrators in the study hospitals who assisted in obtaining written informed consent for the survey and in distributing questionnaires to the subjects. This study was supported by the National Natural Science Foundation of China (71673300).

\section{Disclosure}

The authors report no conflicts of interest in this work.

\section{References}

1. Sharpe M, Wilks D. Fatigue. BMJ. 2002;325(480-483). doi:10.1136/ bmj.325.7362.480

2. Van't Leven M, Zielhuis GA, van der Meer JW, Verbeek AL, Bleijenberg G. Fatigue and chronic fatigue syndrome-like complaints in the general population. Eur J Public Health. 2010;20(3):251-257. doi:10.1093/eurpub/ckp113

3. Wong WS, Fielding R. Prevalence of chronic fatigue among Chinese adults in Hong Kong: a population-based study. J Affect Disord. 2010;127(1-3):248-256. doi:10.1016/j.jad.2010.04.029

4. Aaronson LS, Teel CS, Cassmeyer V, et al. Defining and measuring fatigue. Image J Nurs Sch. 1999;31:45-50.

5. Techera U, Hallowell M, Stambaugh N, Littlejohn R. Causes and consequences of occupational fatigue: meta-analysis and systems model. J Occup Environ Med. 2016;58(10):961-973. doi:10.1097/ JOM.0000000000000837

6. Fang J, Qiu C, Xu H, You G. A model for predicting acute and chronic fatigue in Chinese nurses. J Adv Nurs. 2013;69(3):546-558. doi:10.1111/j.1365-2648.2012.06029.x

7. Barker LM, Nussbaum MA. Fatigue, performance and the work environment: a survey of registered nurses. J Adv Nurs. 2010;67 (6):1370-1382. doi:10.1111/j.1365-2648.2010.05597.x

8. Chen J, Davis KG, Daraiseh NM, Pan W, Davis LS. Fatigue and recovery in $12 \mathrm{hr}$ dayshift hospital nurses. J Nurs Manag. 2014;22 (5):593-603. doi:10.1111/jonm.12062

9. Fang J, Kunaviktikul W, Olson K, Chontawan R, Kaewthummanukul T. Factors influencing fatigue in Chinese nurses. Nurs Health Sci. 2008;10(4):291-299. doi:10.1111/j.1442-2018.2008.00407.x

10. Finsterer J, Mahjoub SZ. Fatigue in healthy and diseased individuals. $A m J$ Hosp Palliat Care. 2014;31(5):562-575. doi:10.1177/1049909113494748

11. Xue H, Dai XJ. Research progress of fatigue perceived by nursing staff and the influencing factors. $J$ Nurs Sci. 2012;27:92-94. [Article in Chinese].

12. Piko BF. Burnout, role conflict, job satisfaction and psychosocial health among Hungarian health care staff: a questionnaire survey. Int $J$ Nurs Stud. 2006;43(3):311-318. doi:10.1016/j.ijnurstu.2005.05.003

13. Gao YQ, Pan BC, Sun W, Wu H, Wang JN, Wang L. Depressive symptoms among Chinese nurses: prevalence and the associated factors. $J$ Adv Nurs. 2012;68(5):1166-1175. doi:10.1111/j.1365-2648.2011.05832.x

14. Bültmann U, Kant IJ, Schröer CA, Kasl SV. The relationship between psychosocial work characteristics and fatigue and psychological distress. Int Arch Occup Environ Health. 2002;75(4):259-266. doi:10.1007/s00420-001-0294-0

15. Zhou CF, Fang JB. Correlation between job characteristics and occupational fatigue in nurses. Hu Li Za Zhi. 2015;62:41-50. [Article in Chinese].

16. Wu S, Zhu W, Wang Z, Wang M, Lan Y. Relationship between burnout and occupational stress among nurses in China. $J A d v$ Nurs. 2007;59(3):233-239. doi:10.1111/j.1365-2648.2007.04301.x

17. Siegrist J. Adverse health effects of high-effort/low-reward conditions. J Occup Health Psychol. 1996;1(1):27-41.

18. Rasmussen V, Turnell A, Butow P, et al. Burnout among psychosocial oncologists: an application and extension of the effort-reward imbalance model. Psycho-Oncology. 2016;25(2):194-202. doi:10.1002/pon.3902

19. Lidwall U. Effort-reward imbalance, overcommitment and their associations with all-cause and mental disorder long-term sick leave - A casecontrol study of the Swedish working population. Int J Occup Med Environ Health. 2016;29(6):973-989. doi:10.13075/ijomeh.1896.00712

20. Mayer JD, Dipaolo M, Salovey P. Perceiving affective content in ambiguous visual stimuli: a component of emotional intelligence. J Pers Assess. 1990;54(3-4):772-781. doi:10.1080/00223891.1990.9674037 
21. Hong E, Lee YS. The mediating effect of emotional intelligence between emotional labour, job stress, burnout and nurses ' turnover intention. Int $J$ Nurs Pract. 2016;22(6):625-632. doi:10.1111/ijn.12493

22. Zhu Y, Liu C, Guo B, Zhao L, Lou F. The impact of emotional intelligence on work engagement of registered nurses: the mediating role of organisational justice. J Clin Nurs. 2015;24(15-16):21152124. doi:10.1111/jocn. 12807

23. Kozlowski D, Hutchinson M, Hurley J, Browne G. Increasing nurses' emotional intelligence with a brief intervention. Appl Nurs Res. 2018;41:59-61. doi:10.1016/j.apnr.2018.04.001

24. Karimi L, Leggat SG, Donohue L, Farrell G, Couper GE. Emotional rescue: the role of emotional intelligence and emotional labour on well-being and job-stress among community nurses. J Adv Nurs. 2014;70(1):176-186. doi:10.1111/jan.12185

25. Kong F, Zhao J, You X. Trait emotional intelligence and mental distress: the mediating role of positive and negative affect. Int $J$ Psychol. 2012;47(6):460-466. doi:10.1080/00207594.2012.666352

26. Lawal AM, Idemudia ES. The role of emotional intelligence and organisational support on work stress of nurses in Ibadan, Nigeria. Curationis. 2017;40(1):e1-e8. doi:10.4102/curationis.v40i1.1715

27. Sharma J, Dhar RL, Tyagi A. Stress as a mediator between workfamily conflict and psychological health among the nursing staff: moderating role of emotional intelligence. Appl Nurs Res. 2016;30:268-275. doi:10.1016/j.apnr.2015.01.010

28. Görgens-Ekermans G, Brand T. Emotional intelligence as a moderator in the stress-burnout relationship: a questionnaire study on nurses. J Clin Nurs. 2012;21(15-16):2275-2285. doi:10.1111/j.1365-2702.2012.04171.x

29. Chalder T, Berelowitz G, Pawlikowska T, et al. Development of a fatigue scale. J Psychosom Res. 1993;37:147-153.

30. Zhang ZJ. Handbook of Behavioral Medicine Scales. Beijing, China: Chinese Medical Multimedia Press; 2005.

31. Jing MJ, Lin WQ, Wang Q, et al. Reliability and construct validity of two versions of chalder fatigue scale among the general population in Mainland China. Int J Environ Res Public Health. 2016;13(1):pii: E147. doi:10.3390/ijerph13121252

32. Siegrist J, Starke D, Chandola T, et al. The measurement of effortreward imbalance at work: european comparisons. Soc Sci Med. 2004;58(8):1483-1499. doi:10.1016/S0277-9536(03)00351-4

33. Li J, Yang W, Cheng Y, Siegrist J, Cho SI. Effort-reward imbalance at work and job dissatisfaction in Chinese healthcare workers: a validation study. Int Arch Occup Environ Health. 2005;78(3):198-204. doi:10.1007/s00420-004-0581-7

34. Pan B, Shen X, Liu L, Yang Y, Wang L. Factors associated with job satisfaction among university teachers in Northeastern region of China: a cross-sectional study. Int J Environ Res Public Health. 2015;12(10):12761-12775. doi:10.3390/ijerph121012761

35. Law KS, Wong CS, Song LJ. The construct and criterion validity of emotional intelligence and its potential utility for management studies. $J$ Appl Psychol. 2004;89(3):483-496. doi:10.1037/0021-9010.89.3.483

36. Pan WG, Wang T, Wang XP, et al. Identifying the core components of emotional intelligence: evidence from amplitude of low-frequency fluctuations during resting state. PLoS One. 2014;9(10):e111435. doi:10.1371/journal.pone.0111435

37. Cella M, Chalder T. Measuring fatigue in clinical and community settings. J Psychosom Res. 2010;69(1):17-22. doi:10.1016/j. jpsychores.2009.10.007

38. Borsini A, Hepgul N, Mondelli V, Chalder T, Pariante C. Recent stressful events contribute to the development of fatigue and depression in patients receiving Interferon- $\alpha$ treatment. Brain Behav Immun. 2013;32:e21-e22. doi:10.1016/j.bbi.2013.07.086
39. Ali S, Matcham F, Irving K, Chalder T. Fatigue and psychosocial variables in autoimmune rheumatic disease and chronic fatigue syndrome: a cross-sectional comparison. J Psychosom Res. 2017;92:1-8. doi:10.1016/j.jpsychores.2016.11.002

40. Leineweber $\mathrm{C}$, Westerlund $\mathrm{H}$, Chungkham HS, Lindqvist R, Runesdotter S, Tishelman C. Nurses' practice environment and work-family conflict in relation to burn out: a multilevel modelling approach. PLoS One. 2014;9(5):e96991. doi:10.1371/journal. pone.0096991

41. Yoder EA. Compassion fatigue in nurses. Appl Nurs Res. 2010;23:191-197. doi:10.1016/j.apnr.2008.09.003

42. Dall'Ora C, Griffiths P, Ball J, Simon M, Aiken LH. Association of $12 \mathrm{~h}$ shifts and nurses' job satisfaction, burnout and intention to leave: findings from a cross-sectional study of 12 European countries. BMJ Open. 2015;5(9):e008331. doi:10.1136/bmjopen-2015-008331

43. Li H, Shao Y, Xing Z, et al. Napping on night-shifts among nursing staff: a mixed-methods systematic review. J Adv Nurs. 2019;75 (2):291-312. doi:10.1111/jan.13859

44. Liu YL. Application of communication skill in new nurse patient relationship. China Health Ind. 2015;6:133-135. [Article in Chinese].

45. Liu L, Chang Y, Fu J, Wang J, Wang L. The mediating role of psychological capital on the association between occupational stress and depressive symptoms among Chinese physicians: a cross-sectional study. BMC Public Health. 2012;12:219. doi:10.1186/14712458-12-219

46. Häusler N, Bopp M, Hämmig O. Effort-reward imbalance, work-privacy conflict, and burnout among hospital employees. J Occup Environ Med. 2018;60(4):e183-e187. doi:10.1097/JOM.0000000000001287

47. Hu S, Wang JN, Liu L, et al. The association between work-related characteristic and job burnout among Chinese correctional officers: a cross-sectional survey. Public Health. 2015;129(9):1172-1178. doi:10.1016/j.puhe.2015.05.006

48. Tang FC, Li RH, Huang SL. The association between job-related psychosocial factors and prolonged fatigue among industrial employees in Taiwan. PLoS One. 2016;11(3):e0150429. doi:10.1371/journal. pone.0150429

49. Wang Y, Ramos A, Wu H, et al. Relationship between occupational stress and burnout among Chinese teachers: a cross-sectional survey in Liaoning, China. Int Arch Occup Environ Health. 2015;88(5):589597. doi:10.1007/s00420-014-0987-9

50. Stavroula L, Jonathan H. Occupational Health Psychology. 2nd ed. Beijing, China: China Light Industry Press; 2014.

51. Gupta R, Singh N, Kumar R. Longitudinal predictive validity of emotional intelligence on first year medical students perceived stress. BMC Med Educ. 2017;17(1):139. doi:10.1186/s12909-0170929-9

52. Li L, Xu P, Zhou K, Xue J, Wu H. Mediating role of emotional labor in the association between emotional intelligence and fatigue among Chinese doctors: a cross-sectional study. BMC Public Health. 2018;18(1):881. doi:10.1186/s12889-018-5817-7

53. Eslami Akbar R, Elahi N, Mohammadi E, Fallahi Khoshknab M. What strategies do the nurses apply to cope with job stress?: a qualitative study. Glob J Health Sci. 2015;8(6):55-64. doi:10.5539/ gjhs.v8n6p55

54. Hammerly ME, Harmon L, Schwaitzberg SD. Good to great: using 360-degree feedback to improve physician emotional intelligence. $J$ Healthc Manag. 2014;59(5):354-365. 


\section{Publish your work in this journal}

Psychology Research and Behavior Management is an international, peer-reviewed, open access journal focusing on the science of psychology and its application in behavior management to develop improved outcomes in the clinical, educational, sports and business arenas. Specific topics covered in the journal include: Neuroscience, memory and decision making; Behavior modification and management; Clinical applications; Business and sports performance management; Social and developmental studies; Animal studies. The manuscript management system is completely online and includes a very quick and fair peer-review system, which is all easy to use. Visit http://www. dovepress.com/testimonials.php to read real quotes from published authors. 